\title{
Identification of A PN 2, the Saccharomyces cerevisiae homolog of the major human AP endonuclease HAP1, and its role in the repair of abasic sites
}

\author{
Robert E. Johnson, Carlos A. Torres-Ramos, Tadahide Izumi, Sankar Mitra, Satya Prakash, \\ and Louise Prakash ${ }^{1}$
}

Sealy Center for Molecular Science, University of Texas M edical Branch, Galveston, Texas 77555-1061 USA

\begin{abstract}
Abasic (AP) sites arise in DNA through spontaneous base loss and enzymatic removal of damaged bases. A PN 1 encodes the major AP-endonuclease of Saccharomyces cerevisiae. Human H A P1 (REF1) encodes the major AP endonuclease which, in addition to its role in DNA repair, functions as a redox regulatory protein. We identify APN 2, the yeast homolog of HAP1 and provide evidence that Apn1 and Apn2 represent altemate pathways for repaining AP sites. The apn1 $1 \Delta$ apn2 $2 \Delta$ strain displays a highly elevated level of MMS-induced mutagenesis, which is dependent on the REV 3, REV 7, and REV 1 genes. Our findings indicate that AP sites are highly cytotoxic and mutagenic in eukaryotes, and that the REV 3, REV 7-encoded DNA polymerase $\zeta$ mediates the mutagenic bypass of AP sites.
\end{abstract}

[Key Words: APN2; APN1; base excision repair; mutagenic bypass; yeast]

Received June 30, 1998; revised version accepted August 14, 1998.

Abasic (AP) sites arise in DNA at a significant rate by spontaneous hydrolysis of the N-glycosylic bond. Extrapolating from the rate of depurination occurring in vitro under physiological conditions, it has been estimated that as many as $10^{4}$ purines are lost spontaneously in a human cell per day (Lindahl and N yberg 1972). AP sites are also formed in DN A as intermediates in base excision repair (BER).

Two major class II AP Endos have been identified in Escherichia coli. exonuclease III, the product of the xth gene, is a constitutive and abundant enzyme representing $\sim 90 \%$ of the total AP activity, and endonuclease IV, encoded by the nfo gene, is an inducible activity representing $10 \%-50 \%$ of the activity in uninduced or induced cells, respectively. Both enzymes also possess a 3'-phosphatase, and a 3'-phosphodi esterase activity that can remove 3 '-terminal groups formed in DNA by free radical attack or by the action of $\beta$-lyase activity associated with some of the DNA glycosylases (Demple and Harrison 1994; Seeberg et al. 1995; Wallace 1997).

Homologs of E. coli exonuclease III and endonuclease IV (Exo III, Endo IV) have been identified in eukaryotes.

${ }^{1}$ Corresponding author.

E-MAIL Iprakash@scms.utmb.edu; FAX (409) 747-8608.
In Saccharomyces cerevisiae, APN 1 encodes the major AP Endo, and it shares extensive homology with Endo IV (Popoff et al. 1990). Like its E. coli counterpart, Apn1 is a class II AP endonuclease, and it has $3^{\prime}$-diesterase, and 3'-phosphatase activities (Johnson and Demple 1988a,b). A homolog of E. coli Exo III has not yet been identified in yeast. In contrast to yeast, Exo III homologs have been identified from mammalian and other sources. The enzyme from humans, variously known as HAP1, APE, Ref-1, or A pex, has a robust class II AP endonuclease activity, but its 3'-phosphodi esterase and 3'-phosphatase activities are relatively weak (Chen et al. 1991; Winters et al . 1994). Interestingly, HAP1 al so functions as a regulatory protein, stimulating the DNA-binding activity of AP-1 proteins, such as c-Jun and c-Fos, by a redox-dependent mechanism (Xanthoudakis and Curran 1992). The stimulatory effect of HAP1 on Jun and Fos is mediated through reduction of a conserved cysteine residue present in the DNA-binding domain of each protein (A bate et al. 1990; Xanthoudakis et al. 1992). HAP1 al so stimulates the DNA-binding activity of other redox regulated transcription factors, including p53 (Xanthoudakis et al. 1992; Jayaraman et al. 1997). The DN A repair and redox activities of HAP1 reside in distinct regions of the protein and can function independently of one another (Walker et al. 1993; Xanthoudakis et al. 1994). HAP1 is 
essential for the early embryonic development of mice, as mice lacking a functional HAP1 gene die shortly after implantation (Xanthoudakis et al. 1996). Because sequences containing both the DN A repair and redox regulatory activities have been disrupted in these mutant mice, it is not known whether one or both of these activities are necessary for embryonic development.

Here we identify a homolog of Exo III/HAP1 in S. cerevisiae, which we have named APN2, and examine the effects of apn $1 \Delta$ and apn $2 \Delta$ mutations on viability, mutagenesis, and the repair of AP sites.

\section{Results}

APN 2 is a member of the Exo III family of AP endonucleases

The S. cerevisiae APN2-encoded protein is homologous to E. coli Exo III (Xth), human HAP1, and to the other related enzymes from Drosophila, Arabidopsis, and other bacterial species (Fig. 1). The HAP1 protein from residues 62-318 retains all of the DN A repair activities (Walker et al. 1993; Xanthoudakis et al. 1994; Izumi and Mitra 1998). This region of $\sim 250$ residues is highly con- served among HAP1, Apn2, Exo III, and other members of the family (Fig. 1A,B). In this regi on, A pn2 shares $33 \%$ similar and $21 \%$ identical residues with HAP1, and $26 \%$ similar and $19 \%$ identical residues with the $\mathrm{E}$. coli Xth protein.

From the x-ray crystal structure of Exo III, residues Asp-229 and His-259 have been proposed to mediate catalysis, and Glu-34 to bind a metal ion and to facilitate catalysis (Mol et al. 1995). HAP1 shares considerable structural similarity to Exo III (Gorman et al. 1997). Mutational inactivation of the corresponding HAP1 active site residues Asp-283, His-309, and Glu-96 to al anine has indicated a critical rol e of these residues in catal ysis (Barzilay et al. 1995). These residues and the sequences flanking them have been very highly conserved in Apn2 and in the other members of this nuclease family (Fig. $1 A, B)$. Apn2 and its counterpart from Schizosaccharomyces pombe have a carboxy-terminal domain that is absent in the other homologs (Fig. 1B). This region of the protein may be involved in species-specific protein-protein interactions.

The amino-terminal 61 residues of $\mathrm{HAP} 1$ are absent in Exo III, and this region is not conserved in A pn2 (Fig. 1A). This amino-terminal region of HAPI is important for redox activity but not for DNA repair functions. The
Figure 1. Apn2 is a member of the Exo III/HAP1 family of proteins. (A) Alignment of human HAP1, S. cerevisiae Apn2, and E. coli Exo III (Xth) proteins. Identical and highly conserved residues are highlighted. Amino acid positions are indicated by numbers in parentheses. The conserved residues thought to be involved in catalytic activity (Glu-96, Asp-283, and His-309 in HAP1 protein) are indicated by arrows. The Cys- 65 residue in HAP1 essential for the redox activity is circled and indicated by an asterisk. (B) Schematic alignment of Exo III-type nucleases from various organisms. Boxes represent primary amino acid sequence. N arrow regions indicate unique sequences, whereas larger, shaded, or stippled regions indicate regions of homology among the proteins. The different shades within the boxes indicate independent domains; spaces indicate gaps that were introduced to optimize alignment of the proteins. Protein lengths are indicated by numbers at right. Positions of the highly conserved amino acid sequences $\mathrm{QE}(\mathrm{T} / \mathrm{L} /$ I)K, R(L/I)D, and SDH(C/A)P are indicated. Positions of the redox cysteine residue in human HAP1, and of cysteine residues present at the corresponding position in Drosophila RRP and Arabidopsis thaliana ARP proteins are indicated by the letter $C$ within the alignments.
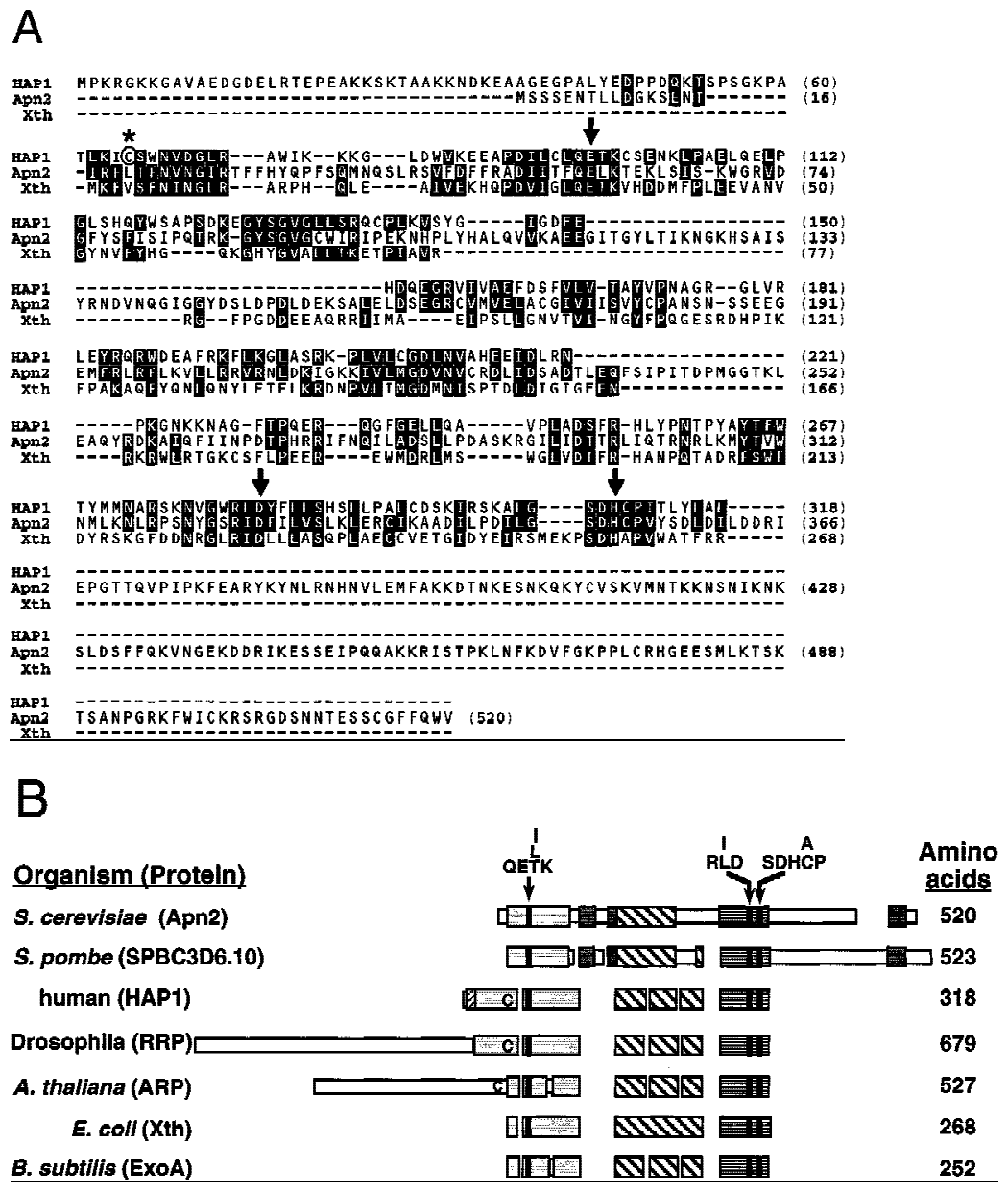
Cys-65 residue present in HAP1 is essential for redox activity, as replacement of this residue with alanine inhibits the ability of HAP1 to stimulate Jun DN A binding (Walker et al. 1993; Xanthoudakis et al. 1994). This cysteine residue is not conserved in Exo III or Apn2. Exo III has no redox activity (Walker et al. 1993), and Apn2 is likely to be devoid of this activity.

\section{APN 2 is not essential for growth or survival}

As previously reported (Ramotar et al. 1991), del etion of APN 1 has no effect on the growth or viability of yeast cells. We have observed no effect of the apn $2 \Delta$ mutation on viability or growth, and the apn $1 \Delta$ apn $2 \Delta$ double mutant also grows normally (data not shown). Because AP sites are noncoding, we determined whether spontaneous mutations arise at a much higher rate in the strains deleted for both of the APN genes. Deletion of APN 1 increased the rate of can $1^{r}$ mutations 3.5-fold, a result similar to that reported previously (Ramotar et al. 1991). The rate of spontaneous can $1^{r}$ mutations in the apn $2 \Delta$ strain was the same as in the wild-type strain, and the apn $1 \Delta$ apn $2 \Delta$ strain exhibited the same level of spontaneous mutability as the apn $1 \Delta$ strain (data not shown).

The apn $2 \Delta$ mutation enhances the sensitivity of the apn $1 \Delta$ strain to alkylation damage

To determine the relative contribution of the APN 1 and APN 2 genes to the repair of AP sites, we tested the sensitivity of the apn $1 \Delta$, apn $2 \Delta$, and apn $1 \Delta$ apn $2 \Delta$ mutant strains to the alkylating agent M MS. M M S al kylates the bases in DNA, particularly adenine at the $\mathrm{N} 3$ position ( $3 \mathrm{M} \mathrm{eA}$ ) and guanine at the $\mathrm{N} 7$ position ( $7 \mathrm{M} \mathrm{eG}$ ). The al kylated bases are removed by the action of $\mathrm{N}$-methylpurine DN A glycosylases (MPG), which act on 3MeA and $7 \mathrm{M} \mathrm{eG}$ and also on a variety of other al kylated bases (Roy et al. 1994; Bjoras et al. 1995). The AP sites resulting from DNA glycosylase action would be acted on by the Apn1 or Apn2 proteins. As shown in Figure 2A, and as reported previously (Ramotar et al . 1991), the apn $1 \Delta$ mutant strain exhibits moderate sensitivity to MMS. The M M S sensitivity of the apn $2 \Delta$ strain is similar to that of the wild-type strain. The apn $1 \Delta$ apn $2 \Delta$ strain, however, displays an extremely enhanced MMS sensitivity, suggesting that $A p n 1$ and $A p n 2$ compete for the repair of $A P$ sites, and in the absence of both AP endonucleases, AP sites remain in DNA and result in cell lethality.

To confirm that the extreme MMS-sensitive phenotype of the apn $1 \Delta$ apn $2 \Delta$ strain was, in fact, attributable to del etions of these two genes, we constructed low copy CEN vectors carrying the wild-type APN 1 or the APN 2 gene, and transformed these plasmids into the apn $1 \Delta$ apn $2 \Delta$ strain to test for complementation. As expected, introduction of the APN 1 plasmid into the apn $1 \Delta$ apn $2 \Delta$ strain restored MMS survival to wild-type levels, whereas introduction of the APN2 plasmid conferred MMS resistance to the level equival ent to that seen in the apn $1 \Delta$ mutant strain (data not shown).
A

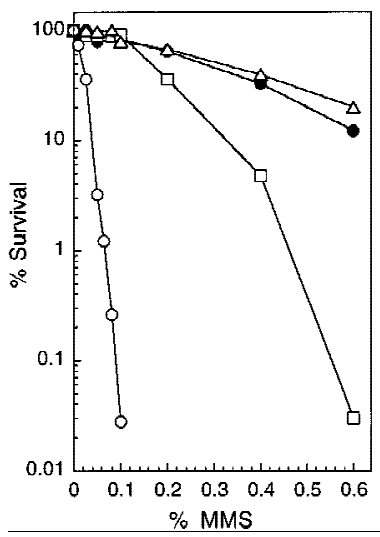

B

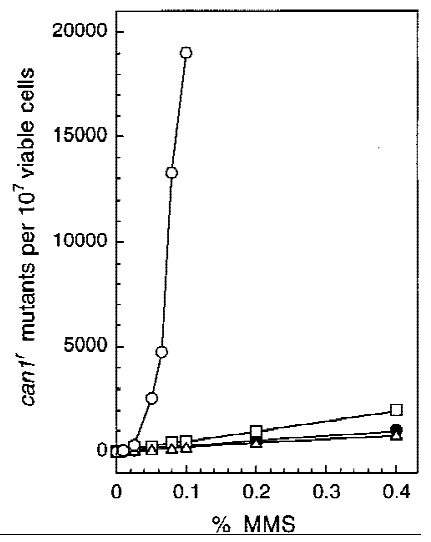

Figure 2. Enhanced M MS sensitivity and M M S mutagenesis in the apn $1 \Delta$ apn $2 \Delta$ strain. (A) MMS sensitivity of various yeast strains. Cells grown overnight in YPD medium were treated with MMS at the concentrations indicated for a 20-min period. A ppropriate dilutions were spread onto YPD plates. Each curve represents the average of two to three experiments for each strain. (@) EMY74.7, wild type (APN1 APN2); ( $\square$ ) YRP190, apn1s; ( $\triangle$ ) YRP263, apn2s; (O) YRP269, apn1s apn2s. (B) MMS-induced mutations at the CAN 1 locus. Cells grown overnight in YPD medium were treated with MMS at the concentrations indicated for a 20-min period. Appropriate dilutions were spread onto YPD plates for viability determinations and onto synthetic complete medium lacking arginine and containing canavanine for the determination of $\mathrm{CAN}^{\mathrm{S}}$ to can $1^{\mathrm{r}}$ mutagenesis. Each curve represents the average of two to three experiments for each strain. (O) EMY74.7, wild type (APN 1 APN2); ( $\square$ ) YRP190, apn1s; ( $\triangle$ ) YRP263, apn2s; (O) YRP269, apn $1 \Delta$ apn $2 \Delta$.

Enhanced MMS-induced mutagenesis in the apn1s apn2 $\Delta$ strain

Because AP sites are noncoding, they would present a block to the DNA replicational machinery. Replication through such sites could occur by a mutagenic process in which DNA polymerase misincorporates a nucleotide opposite such a lesion, or these sites may be bypassed by error-free postreplicative repair processes in which the gap left opposite the AP site is filled in either by a 'copy choice' type of DN A synthesis in which the undamaged sister duplex is used as the template for copying the missing information (Higgins et al . 1976) or by a recombinational mechanism. To evaluate the extent to which AP sites are mutagenic in eukaryotes, we determined the

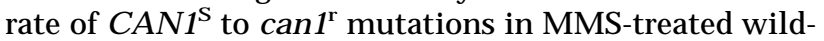
type, apn $1 \Delta, \operatorname{apn} 2 \Delta$, and apn $1 \Delta$ apn2 2 strains (Fig. 2B). The incidence of M M S-induced can $1^{r}$ mutations was the same in the wild-type and apn $2 \Delta$ strains, and was elevated only slightly in the apn $1 \Delta$ strain. In contrast, the frequency of M MS-induced can $1^{r}$ mutations rose sharply in the apn $1 \Delta$ apn2 $2 \Delta$ strain. For instance, whereas treat-

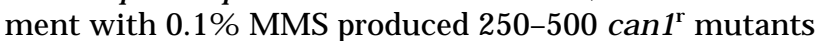
per $10^{7}$ viable cells in the wild-type, apn $1 \Delta$, and apn $2 \Delta$ strains, the can $1^{r}$ mutation frequency rose to 19,000 per 
$10^{7}$ cells in the apn $1 \Delta$ apn $2 \Delta$ strain (Fig. 2B). Introduction of the APN 1 or the APN2 gene carried on a CEN plasmid into the apn $1 \Delta$ apn $2 \Delta$ strain lowered M MS mutagenesis to levels seen in the wild-type and the apn $1 \Delta$ strain, respectively (data not shown). These findings provide the first clear evidence of the high mutagenic potential of unrepaired AP sites in eukaryotes.

Defective repair of MMS-induced DNA damage in the apn $1 \Delta$ apn $2 \Delta$ mutant strain

The greatly enhanced MMS sensitivity of the apn $1 \Delta$ apn $2 \Delta$ mutant strain suggested that both $A p n 1$ and $A p n 2$ function in the removal of AP sites from DNA. To directly assess the role of these nucl eases in the repair of AP sites, we examined the level of AP sites in MMStreated wild-type, apn $1 \Delta$, apn $2 \Delta$, and apn $1 \Delta$ apn $2 \Delta$ mutant strains by sedimentation of DNA in alkaline sucrose gradients. Because $\mathrm{N} \mathrm{aOH}$ hydrol yzes the phosphodiester bond near each AP site, the size reduction in DN A observed on sedimentation in alkaline sucrose gradients is a good measure of the AP sites present. Yeast cells were treated with $0.1 \%$ MMS for $20 \mathrm{~min}$, and the sedimentation profile of DNA was evaluated immediately following this treatment, and following incubation of these cells for an additional 1 or $2 \mathrm{hr}$ to allow time for DNA repair to occur (Fig. 3). In all of the strains, DNA from M M S-treated cells sediments toward the top of the gradient, indicating the presence of AP sites. The sedimentation pattern of DNA obtained from wild-type or apn2 $2 \Delta$ cells that had been incubated for $1 \mathrm{hr}$ following MMS treatment was the same as that of DNA from untreated control cells, indicating proficient repair of AP sites in both these strains during the 1-hr period (Fig. 3A,C). As previously reported (Ramotar et al. 1991), removal of AP sites was less efficient in the apn1s strain. DN A obtained from M MS-treated apn1 $\Delta$ cells that were all owed a 1-hr repair period sedimented at a slower rate than DNA from untreated cells. The size of DNA increased in cells that had been incubated for $2 \mathrm{hr}$ after M M S treatment, but even after this longer repair period, DN A was not fully restored to normal size (Fig. 3B). The removal of AP sites was severely impaired in the apn $1 \Delta$ apn $2 \Delta$ mutant strain, as DN A from M M S-treated apn $1 \Delta$ apn $2 \Delta$ cells all owed a 2 -hr repair period sedi mented only slightly faster than DNA from cells that were treated with MMS but allowed no repair period (Fig. 3D).

Requirement of REV genes in mutagenic bypass of AP sites

Recent in-vitro studies with mammalian DN A polymerase $\delta(\mathrm{Pol} \delta)$ and proliferating cell nuclear antigen (PCNA) have indicated that PCN A allows Pol $\delta$ to replicate past an AP site present in the template strand, resulting in the formation of full-length product (Mozzherin et al. 1997). As expected from the A-rule (Strauss 1991), fully extended primers incorporated predominantly dAM P opposite the template lesion. Exten-
A

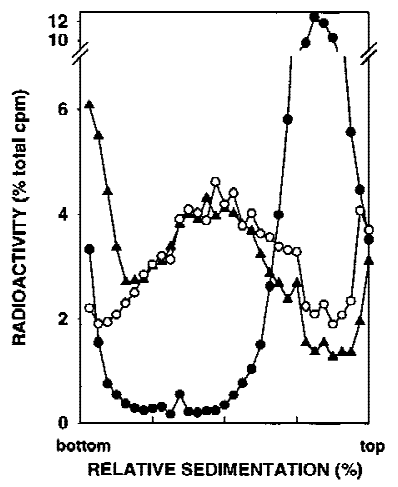

B

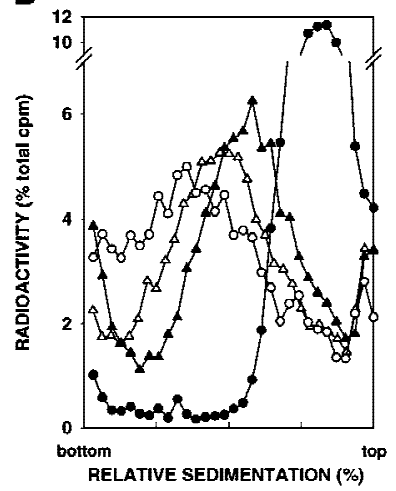

C

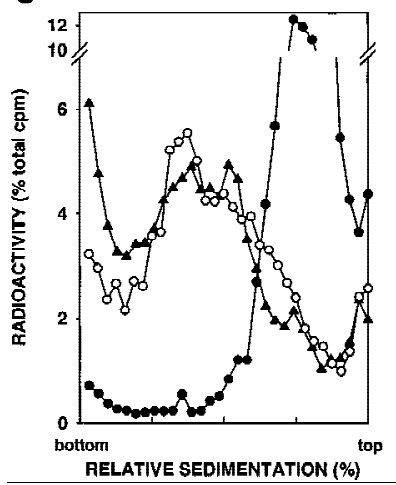

D

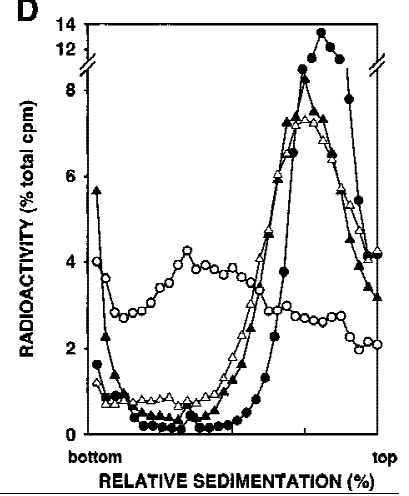

Figure 3. Alkaline sucrose gradient analysis of DNA from cells treated with $0.1 \%$ MMS for $20 \mathrm{~min}$. (A) YRP276, wild type (APN 1 APN2). (B) YRP210, apn1 $\Delta$. (C) YRP291, apn2s. (D) YRP292, apn1 $\Delta$ apn2 2 . (O) Untreated cells; $(\bullet)$ cells treated with MMS for $20 \mathrm{~min}$; $(\mathbf{\Lambda})$ cells treated with MMS for $20 \mathrm{~min}$, and then given a 1-hr repair period; $(\triangle)$ cells treated with MMS for $20 \mathrm{~min}$, and then given a 2-hr repair period.

sive genetic studies in yeast, however, have provi ded evidence for the involvement of REV3, REV7, and REV1 genes in mutagenesis induced by UV light (Lawrence and Hinkle 1996). M ore recent biochemical studies have indicated that Rev3 and Rev7 consitute two subunits of DN A Pol $\zeta$, which has the ability to replicate past a thymine cis-syn cyclobutane dimer ( $\mathrm{N}$ elson et al. 1996b). Rev1 has a deoxycytidyl transferase activity, and it transfers a dCM P residue to the $3^{\prime}$ end of a primer in a template-dependent reaction. Interestingly, the enzyme efficiently inserts dCMP opposite an AP site, producing a terminus that can be extended by $\mathrm{Pol} \zeta$ ( $\mathrm{N}$ el son et al. 1996a).

The availablity of the apn $1 \Delta$ apn $2 \Delta$ strain has provided us the opportunity to test whether mutagenic bypass of AP sites is mediated by the Rev proteins. To examine this, we incorporated the rev $3 \Delta$, rev7 $7 \Delta$, and $\operatorname{rev} 1 \Delta$ mutations in the apn $1 \Delta$ apn $2 \Delta$ strain, and examined the incidence of M M S-induced mutations. As shown in Figure 4, the rev3 $3 \Delta$, rev7 $\Delta$, or rev $1 \Delta$ mutations did not enhance the MMS sensitivity of apn $1 \Delta$ apn $2 \Delta$ strain, but, interestingly, no MMS-induced can $1^{r}$ mutations were recovered in any of these apn $1 \Delta$ apn $2 \Delta \operatorname{rev} \Delta$ mutant strains. 
A

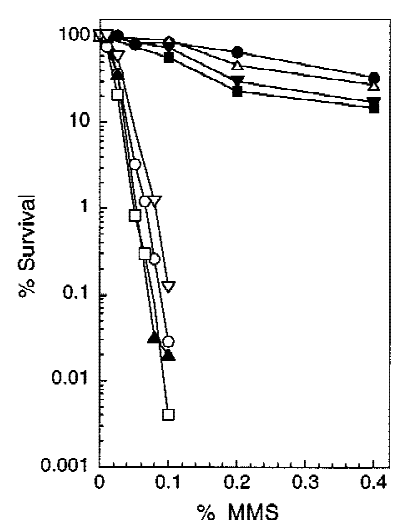

B

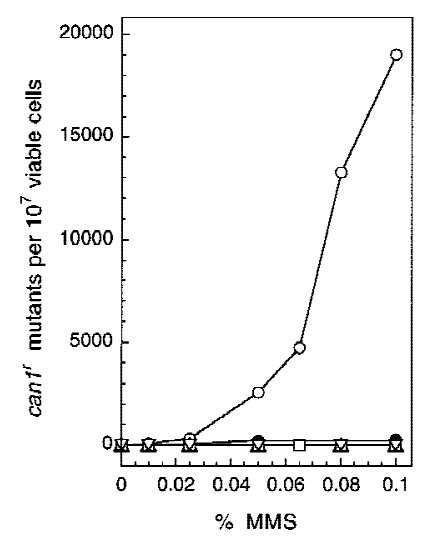

Figure 4. Requirement of REV genes for M MS-induced mutagenesis in the apn $1 \Delta$ apn2 $\Delta$ strains. M ethods are as described in the legend to Fig. 2. (A) M MS sensitivity of yeast strains. (0) EMY74.7, wild type (APN 1 APN2); (O) YRP269, apn1 $1 \Delta$ apn2 2 ; $(\triangle)$ YREV1.15, rev1 $\Delta ;(\boldsymbol{\square})$ YREV3.15, rev3 $4 ;(\boldsymbol{\nabla})$ YREV 7.1, rev7 $\Delta$;

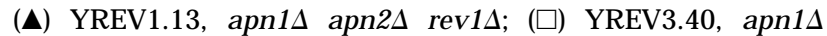
apn2 $\Delta$ rev3 $\Delta ;(\nabla)$ YREV7.4, apn1 $\Delta$ apn2 $\Delta$ rev7 $\Delta$. (B) MMS-induced mutations of CAN $1^{\mathrm{S}}$ to can $1^{\mathrm{r}}$. (O) YRP269, apn1 $1 \Delta$ apn2 2 ; (A) YREV1.13, apn1 $\Delta$ apn2 $\Delta$ rev1 $\Delta$; ( $\square$ ) YREV3.40, apn1 $\Delta$ apn2 $\Delta$ rev3 $\Delta ;(\nabla)$ YREV7.4, apn1 $\Delta$ apn2 $\Delta$ rev7 $\Delta$.

These results indi cate that mutagenic bypass of AP sites is controlled by Pol $\zeta$ and its accessory factors.

\section{Discussion}

AP sites are one of the most common lesions in DNA. To define the pathways for the repair of AP sites in eukaryotes, here we identify yeast APN2, a homolog of E. coli Exo III and human HAP1. Deletion of APN2 has no effect on cell viability or growth, and the apn1 $1 \Delta$ apn2 2 mutant also grows normally. Sensitivity to MMS is not affected by the apn $2 \Delta$ mutation, but the apn $1 \Delta$ apn $2 \Delta$ strain displays a much higher level of sensitivity to M MS than the apn $1 \Delta$ strain, which is only moderately sensitive to this DNA-damaging agent. Consistent with this observation, the apn $1 \Delta$ apn $2 \Delta$ mutant is highly deficient in the removal of AP sites, as determined by alkaline sucrose gradient sedimentation of DNA obtained from MMS-treated cells. These results provide strong evidence for a role of Apn2 in the removal of AP sites, and they indicate that Apn1 and Apn2 represent alternate ways of removing AP sites.

The identification of $A p n 2$ and the demonstration of its involvement in the repair of AP sites in yeast attests to the high degree of conservation of pathways for repairing AP sites among prokaryotes and eukaryotes. Therefore, Exo III in E. coli, Apn 2 in S. cerevisiae, and HAP1 in humans, all function in the removal of AP sites. Even though no Endo IV/Apn1 homolog has yet been indentified in humans and higher eukaryotes, such an activity is likely to be present in there as well. It is of some interest to note that although the enzymes for removing

AP sites, as well as many of the DNA N-glycosylases, have been conserved between prokaryotes and eukaryotes, no such conservation exists among the components of the nucleotide excision repair machinery.

Apn 1 accounts for $>90 \%$ of the class II AP endonuclease/3'-di esterase activity in wild-type yeast cell extracts, suggesting that the activity encoded by APN2 is relatively minor. This is consistent with the observation that deletion of APN 1 increases the rate of spontaneous mutations as well as MMS sensitivity, but deletion of APN 2 has no effect on these phenotypes. In the absence of Apn1, however, cells rely on the repair function of Apn2, as deletion of both the APN1 and APN2 genes elicits a large increase in M MS sensitivity and confers a severe reduction in the ability to remove AP sites. A class II AP endonuclease and 3'-phosphodiesterase activity has been recently partially purified from apn $1 \Delta \mathrm{S}$. cerevisiae cells. Unlike Apn1, but similar to Exo III, this activity is strongly dependent on $\mathrm{Mg}^{2+}$ (Sander and Ramotar 1997). APN2 may encode this activity.

The high level of deficiency in the removal of AP sites in the apn $1 \Delta$ apn $2 \Delta$ strain would predict that spontaneously arising AP sites would accumulate in this strain. It is therefore somewhat surprising that simultaneous inactivation of the APN 1 and APN 2 genes has no effect on cell viability or growth, and spontaneous mutability is increased only a few fold in the apn $1 \Delta$ apn $2 \Delta$ strain. On infliction of additional DNA damage, however, as on treatment with M MS, apn $1 \Delta$ apn $2 \Delta$ cells suffer a drastic reduction in survival, and they display a sharp rise in mutagenesis. We interpret these observations as fol lows. In normally growing apn $1 \Delta$ apn $2 \Delta$ cells, the AP sites resulting from spontaneous base loss can be efficiently handled by postreplicative bypass processes, and a majority of these act in an error-free manner. In MMStreated cells, however, the rising level of AP sites is handled by error-free as well as mutagenic bypass processes, resulting in a steep rise in the incidence of mutations in the surviving apn $1 \Delta$ apn $2 \Delta$ cells and cell death occurs if all the bypass processes are saturated.

Even though in vitro studies have indicated that mammalian DNA Pol $\delta$, in concert with PCNA, can efficiently bypass AP sites (M ozzherin et al. 1997), our genetic studies provide evidence for the requirement of REV 3 and REV7 encoded DN A Pol $\zeta$ and of Rev1 protein in mutagenic bypass of AP sites. Deletion of any of these REV genes in the apn $1 \Delta$ apn $2 \Delta$ strain, however, causes no significant enhancement of M MS sensitivity, suggesting that mutgenic bypass by the REV 3 system makes only a minor contribution to cell survival and that a majority of AP sites are bypassed in an error-free manner. Because AP sites would represent one of the most fre quently formed DNA lesions in mammalian cells (Lindahl and Nyberg 1972), however, DNA Pol $\zeta$-mediated mutagenic bypass of AP sites may make a significant contribution to mutagenesis, and to tumorigenesis and carcinogenesis. The identification of REV3 and REV7 counterparts in humans (Lawrence and Hinkle 1996; Gibbs et al. 1998) supports such a possiblity.

In contrast to the absence of any effect on cell viability 
of the apn $2 \Delta$ mutation either alone or when combined with the apn $1 \Delta$ mutation, mice lacking a functional HAP1 (REF1) gene die during embryonic development, following blastocyst formation (Xanthoudakis et al. 1996). This lethality may arise from a deficiency in the repair of AP sites or of oxidative damage, or from the inactivation of the redox regulatory function, or from the combined effects of these deficiencies. The redox activity of HAP1 protein resides in the amino-terminal domain, and cysteine 65 is essential for this function. Because neither the amino-terminal sequence nor the cysteine 65 residue have been conserved in Apn2, this protein may have no role in redox regulation. Our observations with the yeast apn $1 \Delta$ apn $2 \Delta$ mutant may suggest that embryonic lethal ity of hapl $-1-$ mice results from a deficiency in the redox regulatory function and not from the inactivation of the DNA repair function of HAP1.

\section{Materials and methods}

\section{Identification of APN2}

To identify the yeast homolog of the human AP endonuclease HAP1, the HAP1 protein sequence (GenBank accession no. $M$ 92444) was used to search for homologs in the $S$. cerevisiae nonredundant protein data set at the Saccharomyces Genome Database using the BLAST program (Altschul et al. 1990). TheS. cerevisiae open reading frame (ORF) designated YBL019W (accession no. Z35780) showed homology to HAP1-encoded protein, and we have named this gene APN2.

\section{Generation of yeast null mutations}

Deletion mutations were generated in yeast by the gene replacment method (Rothstein 1991) using the U RA 3 genebl aster. To construct a genomic deletion mutation of APN 1, a 1.9-kb PCR product containing the APN 1 gene was cloned into pUC 19 , generating the plasmid pPM 750. The region of APN 1 from the BglII site at nucleotide position +25 to the EcoRV site at postion +1057 within the APN 1 ORF was replaced with the URA3 geneblaster fragment. The resulting plasmid, pPM 753, when cut with Pvull results in a linear DNA fragment, incorporation of which in the yeast genome del etes APN 1 from nucl eotide +30 to +1060 of the 1104-bp APN 1 ORF. To construct the apn2 deletion generating plasmid, a 2.54-kb PCR product encompassing the APN 2 gene was generated and cloned into pU C 19. The 1.37$\mathrm{kb}$ Bglll fragment within the APN2 ORF was excised and replaced with the URA 3 geneblaster fragment. The apn $2 \Delta$-generating plasmid pPM 838, when digested with BamHI and Sall, rel eases a linear DNA fragment, incorporation of which in the yeast genome deletes APN 2 from nucleotide +135 to +1505 of the 1563-bp APN2 ORF. Linear deletion generating DNA was introduced into yeast strains by the lithium acetate method (Ito et al. 1983). Generation of genomic deletions was confirmed by PCR of genomic DNA. The URA3 geneblaster fragment contains the URA 3 gene flanked by two direct repeats of the Salmonella HisG sequence. These repeats allow for recombination in yeast to excise the URA3 gene (Alani et al. 1987). Loss of the URA 3 gene was selected for by plating cells on medium containing 5-fluoro-orotic acid (5-FOA).

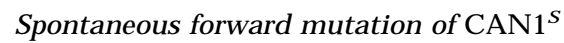

To measure the rates of spontaneous foward mutation at the $\mathrm{CAN}^{\mathrm{S}}$ locus, for each strain, 11 independent cultures were grown in $500 \mu \mathrm{l}$ of $\mathrm{YPD}$, each starting from $\sim 10$ canavaninesensitive cells. Cells were grown for 3 days at $30^{\circ} \mathrm{C}$ and subsequently plated onto synthetic complete (SC) medium lacking arginine but containing canavanine. Plates were incubated for 4-5 days before counting canavanine-resistant colonies. Rates of spontaneous forward mutation were determined by the method of the median (Lea and Coulson 1949). Each experiment was performed in duplicate.

\section{MMS sensitivity and mutagenesis}

All of the strains used for these experiments were derived from DBY 747 that had been made trp1 $\Delta$, resulting in the strain EMY74.7 (MATa his3- $\Delta 1$ leu2-3,-112 trp1 $\Delta$ ura3-52). For determining sensitivity to M MS and for measuring the rate of MMSinduced forward mutations at the $\mathrm{CAN}^{\mathrm{S}}$ locus, cells were grown overnight in YPD medium, sonicated to disperse clumps, washed, and resuspended in $0.05 \mathrm{M} \mathrm{KPO}_{4}$ buffer at pH 7.0. Appropriate dilutions of M MS were added to 1-ml suspensions of cells adjusted to $1.5 \times 10^{8}$ cells per ml. Samples were incubated in the presence of $\mathrm{MMS}$ with vigorous shaking at $30^{\circ} \mathrm{C}$ for 20 $\mathrm{min}$. The reaction was terminated by the addition of $1 \mathrm{ml}$ of $10 \%$ sodium thiosulfate. Appropriate dilutions of cells were plated on YPD for viability determinations and on synthetic complete medium lacking arginine but containing canavanine for determining the frequency of can $1^{r}$ mutations. Plates were incubated at $30^{\circ} \mathrm{C}$ and counted after 3 and $4-5$ days for viability and mutagenesis determinations, respectively.

\section{Alkaline sucrose gradients}

All strains for alkaline sucrose gradient sedimentation were derived from EMY 74.7. $\rho^{0}$ derivatives lacking mitochondrial DNA were obtained by ethidium bromide mutagenesis, resulting in the following isogenic strains used in these experiments: YRP276, his3- $\Delta 1$ leu2-3,-112 trp1 $\Delta$ ura3-52 $\rho^{0}$; YRP210, his3- $\Delta 1$ leu2-3,-112 trp1 $\Delta$ ura3-52 $\rho^{0}$ apn1 $\Delta$; YRP291, his3- $\Delta 1$ leu2-3,$112 \operatorname{trp} 1 \Delta$ ura3-52 $\rho^{0}$ apn2 $\Delta$; Y RP292, his3- $\Delta 1$ leu2-3,-112 trp1 $\Delta$ ura3-52 $\rho^{0}$ apn $1 \Delta$ apn $2 \Delta$. Strains grown overnight at $30^{\circ} \mathrm{C}$ in SC medium containing $10 \mu \mathrm{g} / \mathrm{ml}$ of uracil and $10 \mu \mathrm{Ci} / \mathrm{ml}\left[{ }^{3} \mathrm{H}\right]$ uracil were collected by filtration, washed, and suspended in the same volume of SC containing $30 \mu \mathrm{g} / \mathrm{ml}$ of uracil. Cells were then incubated for $1 \mathrm{hr}$ at $30^{\circ} \mathrm{C}$ to allow for depletion of the intracellular pool of $\left[{ }^{3} \mathrm{H}\right]$ uracil to occur. Cells were collected by filtration, washed, and suspended in $0.05 \mathrm{M} \mathrm{KPO}_{4}$ buffer at $\mathrm{pH}$ 7.0, and incubated for $20 \mathrm{~min}$ with MMS at a final concentration of $0.1 \%$. Cells were collected by filtration, washed, and resuspended in $3 \mathrm{ml}$ of water. One milliliter of cells was used for the 0 -hr sample and the other $2 \mathrm{ml}$ of cells was di luted to $20 \mathrm{ml}$ with YPD medium and incubated for an additional 1 or $2 \mathrm{hr}$ to allow for repair to occur. Conversion of cells to spheroplasts, al kaline sucrose gradient sedimentation, and processing of samples were performed as described (Torres-Ramos et al. 1996), except that acid precipitation of alkali-hydrolyzed samples was carried out with $1 \mathrm{~N} \mathrm{HCl}$ and $0.1 \mathrm{~m}$ sodium pyrophosphate rather than TCA.

\section{Acknowledgments}

This work was supported by grants GM 19261, CA41261, and CA53791 from the $\mathrm{N}$ ational Institutes of Health, ES08547 from the $\mathrm{N}$ ational Institute of Environmental Health Sciences, and grant DEFGO3-93ER61706 from the Department of Energy.

The publication costs of this article were defrayed in part by payment of page charges. This article must therefore be hereby marked 'advertisement' in accordance with 18 USC section 1734 solely to indicate this fact. 


\section{References}

Abate, C., L. Patel, F.J. Rauscher III, and T. Curran. 1990. Redox regulation of Fos and Jun DNA-binding activity in vitro. Science 249: 1157-1161.

Alani, E., L. Cao, and N. Kleckner. 1987. A method for gene disruption that al lows repeated use of URA 3 selection in the construction of multiply disrupted genes. Genetics 116: 541-545.

Altschul, S.F., W. Gish, W. Miller, E.W. Myers, and J. Lipman. 1990. Basic local alignment search tool. J. Mol. Biol. 215: 403-410.

Barzilay, G., C.D. Mol, C.N. Robson, L.J. Walker, R.P. Cunningham, J.A. Tainer, and I.D. Hickson. 1995. Identification of critical active-site residues in the multifuncitonal human DNA repair enzyme HAP1. Nat. Struct. Biol. 2: 561-568.

Bjoras, M., A. Klungland, R.F. Johansen, and E. Seeberg. 1995. Purification and properties of the al kylation repair DN A glycosylase encoded MAG gene from Saccharomyces cerevisiae. Biochemistry 34: 4577-4582.

Chen, D.S., T. Herman, and B. Demple. 1991. Two distinct human DNA diesterases that hydrolyze 3'-blocking deoxyribose fragments from oxidized DNA. Nucleic Acids Res. 19: $5907-5914$.

Demple, B. and L. Harrison. 1994. Repair of oxidative damage to DNA: Enzymology and biology. Annu. Rev. Biochem. 63: 915-948.

Gibbs, P.E.M., W.G. McGregor, V.M. Maher, P. Nisson, and C.W. Lawrence. 1998. A human homolog of the Saccharomyces cerevisiae REV3 gene, which encodes the catalytic subunit of DNA polymerase $\zeta$. Proc. Natl. Acad. Sci. 95: 68766880.

Gorman, M.A., S. Morera, D.G. Rothwell, E. de la Fortelle, C.D. Mol, J.A. Tainer, I.D. Hickson, and P.S. Freemont. 1997. The crystal structure of the human DNA repair endonuclease HAP1 suggests the recognition of extra-helical deoxyribose at DNA abasic sites. EMBO J. 16: 6548-6558.

Higgins, N.P., K. Kato, and B. Strauss. 1976. A model for replication repair in mammalian cells. J. Mol. Biol. 101: 417-425.

Ito, H., Y. Faukuda, K. Murata, and A. Kimura. 1983. Transformation of intact yeast cells treated with alkali cations. J. Bacteriol. 153: 163-168.

Izumi, T. and S. Mitra. 1998. Deletion analysis of human APendonuclease: Minimum sequence required for the endonuclease activity. Carcinogenesis 19: 525-527.

Jayaraman, L., K.G.K. Murthy, C. Zhu, T. Curran, S. Xanthoudakis, and C. Prives. 1997. Identification of redox/repair protein Ref-1 as a potent activator of p53. Genes \& Dev. 11: $558-570$.

Johnson, A.W. and B. Demple. 1988a. Yeast DNA 3'-repair diesterase is the major cellular apurinic/apyrimidinic endonuclease: Substrate specificity and kinetics. J. Biol. Chem. 263: 18017-18022.

Johnson, A.W. and B. Demple. 1988b. Yeast DN A diesterase for 3 '-fragments of deoxyribose: Purification and physical properties of a repair enzyme for oxidative DNA damage. J. Biol. Chem. 263: 18009-18016.

Lawrence, C.W. and D.C. Hinkle. 1996. DNA polymerase $\zeta$ and the control of DN A damage induced mutagenesis in eukaryotes. Cancer Surv. 28: 21-31.

Lea, D.E. and C.A. Coulson. 1949. The distribution of the numbers of mutants in bacterial populations. J. Genet. 49: 264285.

Lindahl, T. and B. N yberg. 1972. Rate of depurination of native deoxyribonucleic acid. Biochemistry 11: 3610-3617.

Mol, C.D., C.-F. Kuo, M.M. Thayer, R.P. Cunningham, and J.A.
Tainer. 1995. Structure and function of the multifunctional DN A-repair enzyme exonuclease III. N ature 374: 381-386.

Mozzherin, D.J., S. Shibutani, C.-K. Tan, K.M. Downey, and P.A. Fisher. 1997. Proliferating cell nuclear antigen promotes DNA synthesis past template lesions by mammalian DN A polymerase $\delta$. Proc. Natl. Acad. Sci. 94: 6126-6131.

N elson, J.R., C.W. Lawrence, and D.C. Hinkle. 1996a. Deoxycytidyl transferase activity of yeast REV1 protein. Nature 382: 729-731.

_-_. 1996b. Thymine-thymine dimer bypass by yeast DNA polymerase $\zeta$. Science 272: 1646-1649.

Popoff, S.C., A.I. Spira, A.W. Johnson, and B. Demple. 1990. Yeast structural genes (APN 1) for the major apurinic endonuclease: Homology to Escherichia coli endonuclease IV. Proc. Natl. Acad. Sci. 87: 4193-4197.

Ramotar, D., S.C. Popoff, E.B. Gralla, and B. Demple. 1991. CelIular role of yeast A pn 1 apurinic endonuclease/3' -di esterase: Repair of oxidative and alkylation DN A damage and control of spontaneous mutation. Mol. Cell. Biol. 11: 4537-4544.

Rothstein, R. 1991. Targeting, disruption, replacement, and allele rescue: Integrative DNA transformation in yeast. Methods Enzymol. 194: 281-301.

Roy, R., C. Brooks, and S. Mitra. 1994. Purification and biochemical characterization of recombinant $\mathrm{N}$-methylpurineDNA glycosylase of the mouse. Biochemistry 33: 1513115140.

Sander, M. and D. Ramotar. 1997. Partial purification of Pdel from Saccharomyces cerevisiae: Enzymatic redundancy for the repair of $3^{\prime}$-terminal DNA lesions and abasic sites in yeast. Biochemistry 36: 6100-6106.

Seeberg, E., L. Eide, and M. Bjorås. 1995. The base excision repair pathway. Trends Biochem. Sci. 20: 391-396.

Strauss, B.S. 1991. The 'A-rule' of mutagen specificity: A consequence of DNA polymerase bypass of non-instructional lesions? BioEssays 13: 79-84.

Torres-Ramos, C.A., B.L. Yoder, P.M .J. Burgers, S. Prakash, and L. Prakash. 1996. Requirement of proliferating cell nuclear antigen in RAD6-dependent postreplicational DNA repair. Proc. Natl. Acad. Sci. 93: 9676-9681.

Walker, L.J., C.N . Robson, E. Black, D. Gillespie, and I.D. Hickson. 1993. Identification of residues in the human DNA repair enzyme HAP1 (Ref-1) that are essential for redox regulation of Jun DNA binding. Mol. Cell. Biol. 13: 5370-5376.

Wallace, S. 1997. Oxidative damage to DNA and its repair. In Oxidative stress defenses (ed. J.G. Scandalios), pp. 49-90. Cold Spring Harbor Laboratory Press, Cold Spring Harbor, NY.

Winters, T.A., W.D. Henner, P.S. Russell, A. McCullough, and T.J. Jorgensen. 1994. Removal of 3'-phosphoglycolate from DNA strand-break damage in an oligonucleotide substrate by recombinant human apurinic/apyrimidinic endonuclease 1. Nucleic Acids Res. 22: 1866-1873.

Xanthoudakis, S. and T. Curran. 1992. Identification and characterization of Ref-1, a nuclear protein that facilitates AP-1 DNA-binding activity. EMBO J. 11: 653-665.

Xanthoudakis, S., G. Miao, F. Wang, Y.-C.E. Pan, and T. Curran. 1992. Redox activation of Fos-Jun DNA binding activity is mediated by a DN A repair enzyme. EMBO J. 11: 3323-3335.

Xanthoudakis, S., G.G. Miao, and T. Curran. 1994. The redox and DN A-repair activities of Ref-1 are encoded by nonoverlapping domains. Proc. Natl. Acad. Sci. 91: 23-27.

Xanthoudakis, S., R.J. Smeyne, J.D. Wallace, and T. Curran. 1996. The redox/DNA repair protein, Ref-1, is essential for early embryonic devel opment in mice. Proc. Natl. Acad. Sci. 93: 8919-8923. 


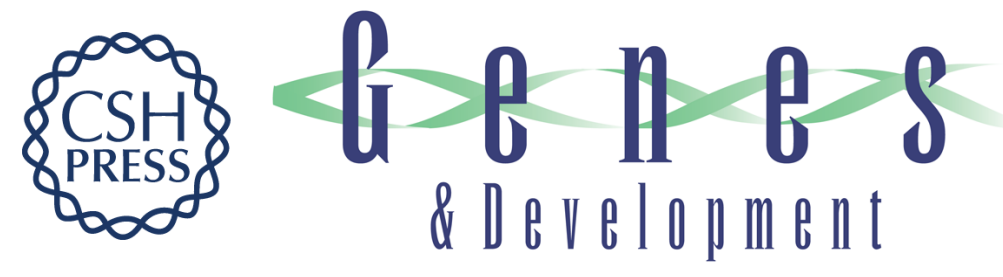

\section{Identification of APN2, the Saccharomyces cerevisiae homolog of the major human AP endonuclease $H A P 1$, and its role in the repair of abasic sites}

Robert E. Johnson, Carlos A. Torres-Ramos, Tadahide Izumi, et al.

Genes Dev. 1998, 12:

Access the most recent version at doi:10.1101/gad.12.19.3137

\section{References This article cites 36 articles, 16 of which can be accessed free at: http://genesdev.cshlp.org/content/12/19/3137.full.html\#ref-list-1}

\section{License}

Email Alerting
Service

Receive free email alerts when new articles cite this article - sign up in the box at the top right corner of the article or click here.

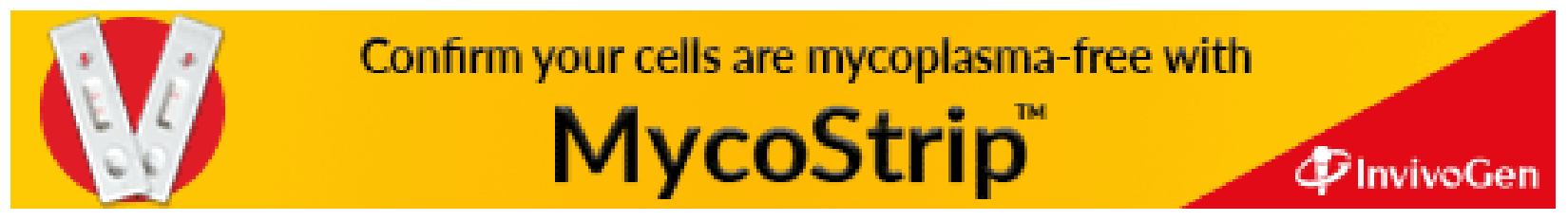

